\title{
Pulmonary Embolism or Pulmonary Thrombosis in COVID-19? Is the Recommendation to Use High- Dose Heparin for Thromboprophylaxis Justified?
}

\author{
Marco Cattaneo ${ }^{1,2}$ Elena M. Bertinato ${ }^{2}$ Simone Birocchi $^{2}$ Carolina Brizio ${ }^{1,2}$ Daniele Malavolta ${ }^{1,2}$ \\ Marco Manzoni ${ }^{1,2}$ Gesualdo Muscarella ${ }^{1,2}$ Michela Orlandi ${ }^{1,2}$
}

\author{
${ }^{1}$ Dipartimento di Scienze della Salute, Università degli Studi di \\ Milano, Milan, Italy \\ 2 Medicina II, ASST Santi Paolo e Carlo-Ospedale San Paolo, \\ Milan, Italy
}

Thromb Haemost 2020;120:1230-1232.
Acutely ill medical patients are at heightened risk for venous thromboembolism, a term that combines deep vein thrombosis (DVT) and its more severe complication, pulmonary embolism. ${ }^{1,2}$ Although the incidence of venous thromboembolism in medical patients might have been overestimated in some instances, according to a recent study, ${ }^{3}$ treatment by low, prophylactic doses of low molecular weight heparin (LMWH) is recommended for these patients when additional risk factors coexist. ${ }^{1,2}$ COVID-19 is an acute, complex disorder that is associated with SARS-CoV-2 infection, which, in its most severe presentation, is characterized by the development of interstitial pneumonia and acute respiratory distress syndrome. ${ }^{4}$ According to many reports, COVID-19 exposes patients to a particularly high risk for venous thromboembolism. $^{5-8}$ Hence, hospitalized COVID-19 patients are generally treated with higher LMWH doses than recommended for thromboprophylaxis. A recent document by the Italian Drug Agency (AIFA) suggested the use of 80 to $100 \mathrm{mg}$ enoxaparin daily, instead of the usual $40 \mathrm{mg}$, while in some hospitals, even higher, up to full anticoagulant doses of LMWH or unfractionated heparin ${ }^{9}$ are used. In our hospital we use $40 \mathrm{mg}$ enoxaparin daily, as recommended for high-risk, acutely ill medical patients. ${ }^{1,2}$

From the COVID-19 outbreak in Northern Italy until April 14,388 patients have been admitted to our non-intensive care unit (ICU) wards, none of whom developed symptomatic DVT during their hospital stay. As DVT may be asymptomatic in a proportion of patients at risk, we performed leg compression ultrasonography, which failed to detect DVT in any of the 64 tested patients, independently of the severity of their condition and length of in-hospital bed rest ( - Table 1 ). The absence of reports in the literature of DVT in COVID-19 patients under

received

April 19, 2020

accepted after revision

April 23, 2020

Address for correspondence Marco Cattaneo, MD, Dipartimento di Scienze della Salute, Università degli Studi di Milano, Via di Rudinì 8 , 20142 Milan, Italy (e-mail: marco.cattaneo@unimi.it).

LMWH thromboprophylaxis confirms our experience. This is apparently in contrast with the relatively frequent reports of pulmonary embolism in hospitalized COVID-19 patients, ${ }^{5-8}$ which is diagnosed based on the clinical observation of rapid worsening of respiratory insufficiency and blood oxygenation that is out of proportion to the extent of pulmonary infiltration and on the evidence of pulmonary vessel occlusions, generally interpreted as caused by pulmonary emboli, when computed tomography angiography (CTA) is performed. These patients, however, usually do not have symptoms or signs of DVT. As an example, a study of 184 severe COVID-19 patients, all hospitalized in ICU and treated mostly with standard doses of LMWH for thromboprophylaxis, reported a high incidence of venous thromboembolism $(n=28){ }^{5}$ However, only one patient had DVT (diagnosed by compression ultrasonography), while pulmonary embolism (diagnosed by CTA) was by far the most frequent thrombotic event $(n=25)$ (highlighting the importance of performing CTA in symptomatic patients whenever possible), followed by two cases of catheter-related upper extremity venous thrombosis. ${ }^{5}$ The discrepancy between the frequencies of pulmonary embolism and DVT is surprising, because, although pulmonary embolism may occur in the absence of detectable DVT, this happens in only approximately $20 \%$ of studied patients. ${ }^{10}$ Therefore, we question whether the observed pulmonary vessels occlusions that have been described in reports on COVID-19 patients are exclusively caused by pulmonary embolism. In our experience and in some reports, ${ }^{11,12}$ filling defects of pulmonary vessels that are detected by CTA scans are in many instances more reminiscent of pulmonary thrombi rather than emboli, because they are not fully occlusive. This observation is compatible with postmortem descriptions of “...presence of manifestations of

(c) 2020 Georg Thieme Verlag KG Stuttgart · New York
DOI https://doi.org/ 10.1055/s-0040-1712097. ISSN 0340-6245. 
Table 1 Characteristics of 64 hospitalized COVID-19 patients who underwent bilateral leg compression ultrasonography to unravel asymptomatic deep vein thrombosis

\begin{tabular}{|c|c|}
\hline Age $(y)$ & $70[\mathrm{~min}=35 ; \mathrm{max}=97 ; \mathrm{IQR}=58-77.5]$ \\
\hline Days of in-hospital bed rest & $9[\min =1 ; \max =45 ; \mathrm{IQR}=4-15]$ \\
\hline Days in NIV & $0[\min =0 ; \max =20 ; \mathrm{IQR}=0-5]$ \\
\hline Respiratory rate (breaths/min) & $20[\min =8 ; \max =32 ; \mathrm{IQR}=16-24]$ \\
\hline $\mathrm{PaO}_{2} / \mathrm{FiO}_{2}$ & $300[\min =60 ; \max =600 ; \mathrm{IQR}=249-392.5]$ \\
\hline D-dimer $(\mu \mathrm{g} / \mathrm{mL})$ & $0.458[\mathrm{~min}=0.1 ; \max =11.970 ; \mathrm{IQR}=0.252-0.903]$ \\
\hline Fibrinogen $(\mathrm{g} / \mathrm{L})$ & $4.76[\min =1.30 ; \max =9.50 ; \mathrm{IQR}=3.878-5.38]$ \\
\hline Ferritin $(\mu \mathrm{g} / \mathrm{L})$ & $320[\min =30 ; \max =9,000 ; \mathrm{IQR}=185-776]$ \\
\hline Prothrombin time (P/N ratio) & $1.13[\min =0.97 ; \max =1.51 ; \mathrm{IQR}=1.07-1.2]$ \\
\hline Platelet count $\left(\times 10^{9} / \mathrm{L}\right)$ & $286[\min =126 ; \max =754 ; \mathrm{IQR}=222-384]$ \\
\hline Sex & Male $=35 ;$ Female $=29$ \\
\hline Obesity & Yes $=4 ; \mathrm{No}=60$ \\
\hline Previous VTE & $\mathrm{Yes}=0 ; \mathrm{No}=64$ \\
\hline Malignancy & $\mathrm{Yes}=7 ; \mathrm{No}=57$ \\
\hline
\end{tabular}

Abbreviations: IQR, interquartile range; NIV, noninvasive ventilation; VTE, venous thromboembolism.

Note: Median [ $\mathrm{min}=$ lowest value; $\max =$ highest value; $\mathrm{IQR}=$ interquartile range].

thrombotic, or thrombo-hemorrhagic microangiopathy...; ... enlarged pulmonary blood vessels containing microthrombi...." Diffuse thrombotic material is observed also in other organs, compatibly with the development of clinical signs of multiorgan failure. ${ }^{13}$ Therefore, local thrombi both in the lungs and other organs, rather than emboli from peripheral veins, appear to be the hallmark of severe COVID-19, which are responsible for the severe ischemic clinical manifestations of the disease.

Distinction between pulmonary thrombi and pulmonary emboli is not trivial, because their pathogenesis and, hence, treatment are arguably different. If the rarity of DVT in our COVID-19 patients and also in other more severe patients described in the literature strongly suggests that prophylactic LMWH is effective in preventing VTE, it is quite evident that the same treatment is not effective to prevent pulmonary thrombosis in COVID-19 patients. Higher LMWH doses may not be necessarily more effective, considering that anticoagulant doses of heparin are not indicated for treatment of other types of thrombotic microangiopathies, which possibly share some pathogenic mechanisms with the COVID microangiopathy, ${ }^{14}$ with the exception of catastrophic antiphospholipid syndrome. ${ }^{15}$ Pulmonary thrombi in COVID-19 probably develop as a consequence of vascular damage associated with viral infection and severe inflammation, with the pathogenic contribution of platelets interacting with the vascular wall and leukocytes (contributing to boost inflammation), factor XIIa with other components of the contact phase of coagulation, von Willebrand factor, complement, and other players in thromboinflammation, ${ }^{16-24}$ some of which have been shown to be implicated in the pathogenesis of acute respiratory distress syndrome already many years ago. ${ }^{25}$ High-dose heparin in this setting may not only be ineffective, but it may also be dangerous, possibly contributing to the described hemorrhagic component of microangiopathy. While only randomized clinical trials can answer this question, it is well established that high-dose LMWH administration is associated with increased incidence of major and fatal bleeding (which actually occurred in some COVID-19 Italian patients, most likely in association with the high degree of anticoagulation).

Pending the results of randomized clinical trials, which will hopefully test not only high-dose heparin, but also drugs targeting platelets, von Willebrand factor, complement, contact phase of coagulation, and/or other players in thromboinflammation, we believe that we should continue to use $40 \mathrm{mg}$ enoxaparin for thromboprophylaxis of COVID-19 patients, at least in non-ICU wards.

Conflict of Interest

None declared.

\section{References}

1 Kahn SR, Lim W, Dunn AS, et al. Prevention of VTE in nonsurgical patients. Antithrombotic Therapy and Prevention of Thrombosis, 9th ed: American College of Chest Physicians Evidence-Based Clinical Practice Guidelines. Chest 2012;141(2 Suppl):e195S-e226S

2 Schünemann HJ, Cushman M, Burnett $\mathrm{AE}$, et al. American Society of Hematology 2018 guidelines for management of venous thromboembolism: prophylaxis for hospitalized and nonhospitalized medical patients. Blood Adv 2018;2(22): 3198-3225

3 Loffredo L, Arienti V, Vidili G, et al; AURELIO Study Group. Low rate of intrahospital deep venous thrombosis in acutely ill medical patients: results from the AURELIO study. Mayo Clin Proc 2019;94(01):37-43

4 Chen $\mathrm{T}, \mathrm{Wu} \mathrm{D}$, Chen $\mathrm{H}$, et al. Clinical characteristics of 113 deceased patients with coronavirus disease 2019: retrospective study. BMJ 2020;368:m1091

5 Klok FA, Kruip MJHA, van der Meer NJM, et al. Incidence of thrombotic complications in critically ill ICU patients with COVID-19. Thromb Res 2020;191:145-147 
6 Wang T, Chen R, Liu C, et al. Attention should be paid to venous thromboembolism prophylaxis in the management of COVID-19. Lancet Haematol 2020;7(05):e362-e363

7 Wang J, Hajizadeh N, Moore EE, et al. Tissue Plasminogen Activator (tPA) treatment for COVID-19 associated acute respiratory distress syndrome (ARDS): a case series. J Thromb Haemost 2020; 18(07):1752-1755

8 Tang N, Bai H, Chen X, Gong J, Li D, Sun Z. Anticoagulant treatment is associated with decreased mortality in severe coronavirus disease 2019 patients with coagulopathy. J Thromb Haemost 2020;18(05):1094-1099

9 Barrett CD, Moore HB, Yaffe MB, Moore EE. ISTH interim guidance on recognition and management of coagulopathy in COVID-19: a comment. J Thromb Haemost 2020. Doi: $10.1111 /$ jth. 14860

10 Palareti G, Antonucci E, Dentali F, et al. Patients with isolated pulmonary embolism in comparison to those with deep venous thrombosis. Differences in characteristics and clinical evolution. Eur J Intern Med 2019;69:64-70

11 Danzi GB, Loffi M, Galeazzi G, Gherbesi E. Acute pulmonary embolism and COVID-19 pneumonia: a random association? Eur Heart J 2020;41(19):1858

12 Rotzinger DC, Beigelman-Aubry C, von Garnier C, Qanadli SD. Pulmonary embolism in patients with COVID-19: time to change the paradigm of computed tomography. Thromb Res 2020; 190:58-59

13 Du Y, Tu L, Zhu P, et al. Clinical features of 85 fatal cases of COVID19 from Wuhan: a retrospective observational study. Am J Respir Crit Care Med 2020;201(11):1372-1379

14 Masias C, Vasu S, Cataland SR. None of the above: thrombotic microangiopathy beyond TTP and HUS. Blood 2017;129(21): 2857-2863
15 Appel GB. Thrombotic microangiopathies: similar presentations, different therapies. Cleve Clin J Med 2017;84(02):114-130

16 Nilsson B, Teramura Y, Ekdahl KN. The role and regulation of complement activation as part of the thromboinflammation elicited in cell therapies. Mol Immunol 2014;61(02):185-190

17 Hess R, Wujak L, Hesse C, et al. Coagulation factor XII regulates inflammatory responses in human lungs. Thromb Haemost 2017; 117(10):1896-1907

18 Ekdahl KN, Teramura Y, Hamad OA, et al. Dangerous liaisons: complement, coagulation, and kallikrein/kinin cross-talk act as a linchpin in the events leading to thromboinflammation. Immunol Rev 2016;274(01):245-269

19 D' Atri LP, Schattner M. Platelet toll-like receptors in thromboinflammation. Front Biosci 2017;22:1867-1883

20 Suzuki-Inoue K, Tsukiji N, Shirai T, Osada M, Inoue O, Ozaki Y. Platelet CLEC-2: roles beyond hemostasis. Semin Thromb Hemost 2018;44(02):126-134

21 van der Meijden PEJ, Heemskerk JWM. Platelet biology and functions: new concepts and clinical perspectives. Nat Rev Cardiol 2019;16(03):166-179

22 Jackson SP, Darbousset R, Schoenwaelder SM. Thromboinflammation: challenges of therapeutically targeting coagulation and other host defense mechanisms. Blood 2019;133(09):906-918

23 Eriksson O, Mohlin C, Nilsson B, Ekdahl KN. The human platelet as an innate immune cell: interactions between activated platelets and the complement system. Front Immunol 2019;10:1590

24 Guo L, Rondina MT. The era of thromboinflammation: platelets are dynamic sensors and effector cells during infectious diseases. Front Immunol 2019;10:2204

25 McGuire WW, Spragg RG, Cohen AB, Cochrane CG. Studies on the pathogenesis of the adult respiratory distress syndrome. J Clin Invest 1982;69(03):543-553 